\begin{tabular}{|c|l|}
\hline Title & Novel lipidated sorbitol-based molecular transporters for non-viral gene delivery \\
\hline Author(s) & $\begin{array}{l}\text { Higashi, Tomoko; Khalil, I Ikramy A.; Maiti, Kaustabh K.; Lee, Woo Sirl; A kita, Hidetaka; Harashima, Hidey oshi; } \\
\text { Chung, Sung-Kee }\end{array}$ \\
\hline Citation & $\begin{array}{l}\text { Journal of Controlled Release, 136(2), 140-147 } \\
\text { https://doi.org/10.1016/.jconrel.2009.01.024 }\end{array}$ \\
\hline Issue Date & $2009-06-05$ \\
\hline Doc URL & http://hdl.handle.net/2115/38732 \\
\hline Type & article (author version) \\
\hline File Information & 136-2_p140-147.pdf \\
\hline
\end{tabular}

Instructions for use 


\section{Novel Lipidated Sorbitol-based Molecular Transporters for Non-viral Gene Delivery}

Tomoko Higashi ${ }^{\mathrm{a}, \mathrm{b}, 1}$, Ikramy A. Khalil ${ }^{\mathrm{a}, \mathrm{b}, 1}$, Kaustabh K. Maiti ${ }^{\mathrm{c}}$, Woo Sirl Lee ${ }^{\mathrm{c}}$, Hidetaka Akita $^{\mathrm{a}, \mathrm{b}}$, Hideyoshi Harashima ${ }^{\mathrm{a}, \mathrm{b},{ }^{*} \text {, and Sung-Kee Chung }}{ }^{\mathrm{c}, *}$

a Laboratory for Molecular Design of Pharmaceutics, Faculty of Pharmaceutical Sciences, Hokkaido University, Sapporo 060-0812, Japan

${ }^{b}$ Core Research for Educational Science and Technology, Japan Science and Technology Agency, Kawaguchi, Japan

${ }^{\mathrm{c} D}$ Department of Chemistry, Pohang University of Science \& Technology, Pohang 790-784, Korea

${ }^{*}$ Corresponding authors: Laboratory for Molecular Design of Pharmaceutics, Faculty of Pharmaceutical Sciences, Hokkaido University, Kita-12, Nishi-6, Kita-ku, Sapporo 060-0812, Japan, Tel: +81-11-706-3919, Fax: +81-11-706-4879, E-mail: harasima@pharm.hokudai.ac.jp (H. Harashima) and Department of Chemistry, Pohang University of Science \& Technology, Pohang 790-784, Korea, Tel: +82-54-279-2103, Fax: +82-54-279-3399, E-mail: skchung@postech.ac.kr (S K Chung).

${ }^{1}$ These two authors contributed equally to this work. 


\section{ABSTRACT}

In this study, we investigated the possible use of novel lipidated sorbitol-based transporters as functional devices for the improvement of non-viral gene delivery. These transporters are composed of a sorbitol scaffold bearing 8 guanidine moieties that mimic the arginine residues of well-known cell-penetrating peptides. In addition, the transporters carry different lipid groups to aid DNA condensation and facilitate lipid vesicle-binding. We found that the transporters described in this study have the potential to function as plasmid DNA/siRNA-condensers and surface ligands for the enhancement of cellular uptake of lipid vesicles. Shorter lipid chains were found to be better for condensation, whereas longer chains were superior surface ligands. The differential activity of different cores might be explained by facilitated decondensation of cores prepared with transporters comprised of shorter lipid chains. However, we suggest that there is an optimum value of decondensation to achieve higher transfection activities. The proper use of the transporters presented in this study enabled us to prepare a highly efficient non-viral gene delivery system based on a core-shell structure, in which a condensed DNA core is encapsulated by a lipid envelope. A multifunctional envelope-type nano-device prepared with an optimal surface ligand favorably competes with commonly used transfection systems.

\section{Keywords:}

Sorbitol; octaarginine; guanidine; condensation; non-viral gene delivery; MEND 


\section{Introduction}

Therapeutic gene transfer for the treatment of certain human diseases-somatic gene therapy-holds great promise in theory, but its practical application has met with limited success. For example, nearly two dozen children with severe combined immunodeficiency disease (SCID) were apparently cured after injection of retroviral particles carrying the corrective gene into their blood cells. However, three patients subsequently developed leukemia, seemingly because the retrovirus carrier inserts the gene near an oncogene $[1,2]$. The great potential notwithstanding, gene therapy remains highly experimental and presents substantial risk of insertional oncogenesis. In other words, gene therapy is plagued by a paucity of acceptable vector systems for the delivery of nucleic acids to patients. Viral vectors are efficient, but may present significant risk to patients; whereas, synthetic non-viral vectors are inherently safer, but inefficient. Hence, the future of gene therapy depends, at least in part, on the availability of improved non-viral delivery vectors $[3,4]$.

Over the years, a number of cell-penetrating peptides derived from HIV-1 Tat protein, Antennapedia protein of Drosophila, and related peptides, such as arginine oligomers, have been studied for possible improvement of the pharmacokinetic properties of drugs with low bioavailability, including peptides $[5,6]$, proteins $[7,8]$, and nucleic acids [9-13]. Different virus-derived arginine-rich peptides can transfect cells with luciferase-encoding plasmids as efficiently as polyarginine and polylysine [9]. Oligoarginines also effectively transfect cells. Interestingly, stearylation of the octaarginine (R8) peptide at the N-terminus dramatically increased transfection efficiency, such that it approached the efficacy of LipofectAMINE, one of the most efficient commercially available transfection agents [9]. The superiority of stearylated R8 (STR-R8) as a transfection agent over non-lipidated R8 was explained by the formation of hydrophobic cores that more efficiently condensed DNA and tightly bound the cell membrane through both hydrophobic and electrostatic interactions [14]. Using STR-R8 as the primary functional device, we recently developed a multifunctional envelope-type nano-device (MEND) for use as a non-viral gene delivery system [13]. In this system, DNA/polycation cores are encapsulated by a STR-R8-surface modified lipid envelope. The stearyl group is anchored to the lipid membrane, thus leaving the R8 peptide free to interact with the cell surface, resulting in enhanced cellular uptake and controlled intracellular trafficking. The transfection efficiency of MEND modified with STR-R8 was increased 1000-fold higher compared with unmodified MEND [13]. In addition, the presence of high density of R8 peptide on the surface of liposomes stimulates uptake via macropinocytosis, which is an apparent advantage, as lysosomal degradation can be 
avoided [15]. Thus, the efficiency of R8-MEND-mediated transfection of luciferase expression plasmids is comparable to that of adenovirus-mediated transfection with reduced associated cytotoxicity [16].

Although peptide-based molecular transporters are widely used in drug delivery, they present real and potential problems, such as limited in vivo efficacy, susceptibility to endogenous peptidases, and potential neurotoxicity. Hence, a number of synthetic transporters that use molecular scaffolds other than peptide backbones have been developed, e.g. peptoids [17], oligocarbamates [18], and peptide nucleic acids [19]. Very recently, we developed a novel class of guanidine-containing molecular transporters using dimeric-inositol and sorbitol scaffolds. The cellular uptake efficiency of some of these transporters was as good as or better than R8 and R9 in several cell lines, including HeLa cells. However, the uptake mechanism of these novel molecular transporters appears to be substantially different from that of arginine oligomers. The inositol-based transporters are widely distributed in the cytosol, whereas the sorbitol-based transporters are effectively targeted to the mitochondria. In addition, these transporters readily overcome the blood-brain barrier in mice. In other words, depending on the structural elements, such as the scaffold and linker, synthetic transporters exhibit interesting intracellular/organellar- and tissue-selectivity [20-22]. Because of these interesting cellular uptake and intracellular localization properties, we investigated the potential utility of these novel transporters in DNA/gene and siRNA delivery.

To investigate the applicability of sorbitol-based transporters in gene and siRNA delivery using the previously developed MEND system, a long lipid chain must be attached to the transporters, so that they can behave as both a condensing and surface-modifying agent, mediating cellular uptake. Thus, we synthesized the lipidated transporters shown in Fig. 1. The sorbitol scaffold was modified with eight guanidine residues using different types of branched chains. These transporters were further modified with lipid chains that differed in carbon atom number and the presence or absence of a potential protonation site, namely imidazole. In the present study, we systematically evaluated the gene delivery function of these lipidated transporters (1-3). The capability of the transporters as nucleic acid condensing agents and as surface-modifying ligands was compared with our original MEND system in which poly-L-lysine (PLL) and STR-R8 were used as condenser and surface ligand respectively. Based on these studies, the transfection activity of an optimized version of the MEND system was compared to currently available transfection systems. 


\section{Materials and Methods}

\subsection{Materials}

Plasmid DNA (pDNA) pCMV-luc (7037 bp) encoding luciferase were prepared by EndoFree Plasmid Mega Kit (Qiagen, Hilden, Germany). The anti-luciferase siRNA (21mer,

5'-GCGCUGCUGGUGCCAACCCTT-3', 5'-GGGUUGGCACCAGCAGCGCTT-3') and the anti-green fluorescent protein (GFP) SiRNA (5'-GCUGACCCUGAAGUUCAUCTT-3', 5'-GAUGAACUUCAGGGUCAGCTT-3') were obtained from Thermo Electron GmbH (Ulm, Germany). PLL, M.W. 27,400, cholesteryl hemisuccinate (CHEMS) and polyadenylic acid (poly(A) RNA) were obtained from SIGMA-Aldrich (St. Louis, MO). Dioleoyl phosphatidylethanolamine (DOPE) and L- $\alpha$-phosphatidic acid (PA) (from chicken egg, monosodium salt) were purchased from AVANTI Polar Lipids (Alabaster, AL). STR-R8 was synthesized as described previously [9]. Lipofectin Reagent, Dulbecco's modified eagle medium (DMEM) and fetal bovine serum (FBS) were purchased from Invitrogen Corp. (Carlsbad, CA, USA). Luciferase assay reagents and reporter lysis buffer were obtained from Promega Co. (Madison, WI). HeLa human cervix carcinoma cells were obtained from the RIKEN Cell Bank (Tsukuba, Japan). The mouse fibroblasts NIH3T3 cells were obtained from the American Type Culture Collection (Manassas, VA).

2.2 Preparation of lipidated transporters (see Schemes in Supporting Information)

\section{Representative acylation of transporters and removal of protecting groups:}

To a mixture of compound 4 (40 mg, $0.0107 \mathrm{mmol}$ ) [21] and dodecanoic acid (4.3 $\mathrm{mg}, 0.0214 \mathrm{mmol})$ in freshly distilled dichloromethane $(2.5 \mathrm{~mL})$ under $\mathrm{N}_{2}$, were added 1-(3-dimethylaminopropyl)-3-ethylcarbodiimide hydrochloride (EDC) (5.1 mg, 0.0268 mmol) and 4-dimethylaminopyridine (DMAP) (1 mg, $0.0075 \mathrm{mmol})$, and the resulting mixture was stirred at room temperature (RT) for $24 \mathrm{hr}$. The reaction mixture was diluted with EtOAc and washed several times with saturated $\mathrm{NaHCO}_{3}$, water, and brine. The organic phase was separated, dried over $\mathrm{Na}_{2} \mathrm{SO}_{4}$ and concentrated. The crude acylated product was purified by column chromatography on silica gel to afford the acylated intermediate as an off-white foamy solid (33 mg, 78\%).

To a solution of the acylated intermediate $(30 \mathrm{mg}, 0.0076 \mathrm{mmol})$ in EtOAc $(1 \mathrm{~mL})$ at RT, EtOAc (4.5mL) saturated with gaseous $\mathrm{HCl}$ was added. After being stirred for $20 \mathrm{~h}$, the solution was concentrated. The residue was washed with EtOAc and then with a mixture of diethyl ether and $\mathrm{MeOH}(20: 1)$ to remove the less polar impurities. The MPLC 
(reverse phase C8 column)-purified product was dried and dissolved in de-ionized water, filtered again and lyophilized to furnish compound 1a as an off-white foamy solid (HCl salt, $13 \mathrm{mg}, 82 \%$ )

1-O-(Dodecanoyl)-2,3,4,5-tetra-O-\{bis-[2-(2-aminoethylguanidinium-carbamoyl-et hyl)-amino]-hexanoyl\}-D-Sorbitol (1a). Off-white foamy solid (13mg); ${ }^{1} \mathrm{H}-\mathrm{NMR}$ $\left(\mathrm{CD}_{3} \mathrm{OD}\right) \delta 1.24$ (br.s. 24H), 1.33-1.89 (m, 40H), 2.26 (br.s. 8H), 2.82(br.s. 16H), 3.28-3.46 (m, 32H, overlapped with $\mathrm{CD}_{3} \mathrm{OD}$ peak at 3.31), 4.02-4.24 ppm (m, 4H); MS(MALDI-TOF) $\mathrm{m} / \mathrm{z}$ calcd. for $\mathrm{C}_{90} \mathrm{H}_{176} \mathrm{~N}_{36} \mathrm{O}_{19} \mathrm{Na} 2089.59$, found $2088.89[\mathrm{M}+\mathrm{Na}]^{+}$

1-O-(tetracosanoyl)-2,3,4,5-tetra-O-\{bis-[2-(2-aminoethylguanidinium-carbamoyl-e thyl)-amino]-hexanoyl\}-D-Sorbitol (1b). Off-white foamy solid (14mg); ${ }^{1} \mathrm{H}-\mathrm{NMR}\left(\mathrm{CD}_{3} \mathrm{OD}\right) \delta 1.25$ (s, 44H), 1.30-1.88 (m, 43H), 2.28-2.50 (m, 16H), 2.88 (br.s., $16 \mathrm{H}), 3.02$ (br.s., $2 \mathrm{H}), 3.32-3.56$ (m, 32H, overlapped with $\mathrm{CD}_{3} \mathrm{OD}$ peak), 4.00-4.22 ppm (m, 4H); MS(MALDI-TOF): $\mathrm{m} / \mathrm{z}$ calcd. for $\mathrm{C}_{102} \mathrm{H}_{200} \mathrm{~N}_{36} \mathrm{O}_{19} \mathrm{Na} 2257.90$, found $2257.85[\mathrm{M}+\mathrm{Na}]^{+}$

1-O-(triacontanoyl)-2,3,4,5-tetra-O-\{bis-[2-(2-aminoethylguanidinium-carbamoyl-e thyl)-amino]-hexanoyl\}-D-Sorbitol (1c). White foamy solid (16mg); ${ }^{1} \mathrm{H}-\mathrm{NMR}$ $\left(\mathrm{CD}_{3} \mathrm{OD}\right) \delta 1.22$ (br.s. 59H), 1.38-1.91 (m, 40H), 2.22-2.39 (m, 16H), 2.71-2.93 (m, 16H), 3.30-3.51 (m, 32H, overlapped with $\mathrm{CD}_{3} \mathrm{OD}$ peak), 3.89-4.12 ppm (m, 4H); MS(MALDI-TOF) $\mathrm{m} / \mathrm{z}$ calcd. for $\mathrm{C}_{108} \mathrm{H}_{212} \mathrm{~N}_{36} \mathrm{O}_{19} \mathrm{Na} 2342.06$, found $2342.65[\mathrm{M}+\mathrm{Na}]^{+}$

1-O-(triacontanoyl)-2,3,4,5-tetra-O-\{bis-[2-(2-aminoethylguanidinium-carbamoyl-e thyl)-amino]-hexanoyl\}-6-O-(N-Cbz-L-histidyl)-D-Sorbitol (2).

Compound 4 (55 mg, $0.0148 \mathrm{mmol}$ ) was acylated with triacontanoic acid, as previously described. The trityl protecting group was selectively removed by treatment with $1 \%$ TFA in distilled dichloromethane over a $\mathrm{SiO}_{2}$ column at RT. The effluent was washed with saturated $\mathrm{NaHCO}_{3}$ and water, dried over $\mathrm{Na}_{2} \mathrm{SO}_{4}$ and concentrated. The residue was purified by using column chromatography on silica gel to afford an off-white, sticky solid (35 mg, 68\%): $R_{f} 0.33\left(\mathrm{CH}_{2} \mathrm{Cl}_{2}: \mathrm{MeOH}=9: 1\right) ;{ }^{1} \mathrm{H}-\mathrm{NMR}\left(\mathrm{CDCl}_{3}\right): \delta 1.21-1.44(\mathrm{~m}, 224 \mathrm{H})$, $2.02-2.43(\mathrm{~m}, 36 \mathrm{H}), 2.65-2.74(\mathrm{~m}, 16 \mathrm{H}), 3.32-3.44(\mathrm{~m}, 32 \mathrm{H}), 3.98-4.33(\mathrm{~m}, 4 \mathrm{H})$, 4.72-4.80 (m, 2H), 5.18-5.26 (m, 2H), 7.84 (br.s., 8H), 8.48 (br.s., 8H), 11.33 ppm (br.s., $8 \mathrm{H}$ ); MS(MALDI-TOF): $\mathrm{m} / \mathrm{z}$ calcd. for $\mathrm{C}_{188} \mathrm{H}_{340} \mathrm{~N}_{36} \mathrm{O}_{51} \mathrm{Na}$ 3943.92, found 3943.87[M+Na $]^{+}$

A solution of the sticky solid product obtained above (33 $\mathrm{mg}, 0.0084 \mathrm{mmol}$ ), $\mathrm{N}$-carboxybenzoyl-L-histidine (5.3 mg, $0.0185 \mathrm{mmol}$ ), EDC (4.8 mg, $0.02524 \mathrm{mmol}$ ) and DMAP (1 mg, $0.0084 \mathrm{mmol})$ in distilled dichloromethane $(2.5 \mathrm{~mL})$ was stirred at RT under $\mathrm{N}_{2}$-atmosphere. After $30 \mathrm{~h}$, the reaction mixture was diluted with EtOAc and 
washed several times with saturated $\mathrm{NaHCO}_{3}$ followed by washing with water and brine. The organic phase was collected, dried over $\mathrm{Na}_{2} \mathrm{SO}_{4}$ and concentrated. The crude product was purified by column chromatography on silica gel to afford the desired histidine containing compound as off-white foamy solid (28mg, 80\%): $R_{f} 0.32\left(\mathrm{CH}_{2} \mathrm{Cl}_{2}: \mathrm{MeOH}=\right.$ 9:1); ${ }^{1} \mathrm{H}-\mathrm{NMR}\left(\mathrm{CDCl}_{3}\right) \delta$ 1.26-1.60 (m, 227H), 2.22-2.48 (m, 32H), 2.72 (br.s., $\left.16 \mathrm{H}\right)$, 3.39-3.53 (m, 32H), 4.01-4.27 (m, 4H), 4.82 (br.s., $2 \mathrm{H}), 5.01(\mathrm{~s}, 2 \mathrm{H}), 5.54-5.63(\mathrm{~m}, 2 \mathrm{H})$, 7.27-7.34 (m, 5H), 8.02 (br.s., 9H), 8.38 (br.s., 8H), 11.42 ppm (s, 8H); ${ }^{13} \mathrm{C}-\mathrm{NMR}$ $\left(\mathrm{CDCl}_{3}\right): \delta 23.10,24.93,25.29,26.24,27.16,28.44,28.71,29.60,29.76,30.11,32.33$, $33.93,34.35,40.25,40.81,50.12,53.15,79.75,83.70,83.90,126.30,128.47,128.93$, 153.34, 157.42, 163.51, 173.08, 173.30, 173.67 ppm; MS(MALDI-TOF): $\mathrm{m} / \mathrm{z}$ calcd. for $\mathrm{C}_{202} \mathrm{H}_{353} \mathrm{~N}_{39} \mathrm{O}_{54} \mathrm{Na} 4215.19$, found $4215.81[\mathrm{M}+\mathrm{Na}]^{+}$

The above product was treated with gaseous $\mathrm{HCl}$ in ethyl acetate to provide compound 2 as an off-white foamy solid $(13 \mathrm{mg}):{ }^{1} \mathrm{H}-\mathrm{NMR}\left(\mathrm{CD}_{3} \mathrm{OD}\right): \delta 1.23$ (br.s., 59H), 130-1.92 (m, 40H), 2.18-2.37 (m, 16H), 2.88-3.01 (m, 16H), 3.30-3.56 (m, 32H, overlapped with $\mathrm{CD}_{3} \mathrm{OD}$ peak), 4.01-4.28 (m, 4H), 7.26-7.48 ppm (m, 6H); MS(MALDI-TOF): $m / z$ calcd. for $\mathrm{C}_{122} \mathrm{H}_{225} \mathrm{~N}_{39} \mathrm{O}_{22} \mathrm{Na} 2613.34$, found $2613.04\left[\mathrm{M}^{+}+\mathrm{Na}\right]$

1-O-(triacontanoyl)-2,3,4,5-tetra-O-\{bis-[3-(aminopropylguanidinium)-amino]-hex anoyl\}-D-Sorbitol (3). White foamy solid (12 mg); ${ }^{1} \mathrm{H}-\mathrm{NMR}\left(\mathrm{CD}_{3} \mathrm{OD}\right) \delta 1.19-1.24(\mathrm{~m}$, $85 \mathrm{H}), 1.32-1.96(\mathrm{~m}, 40 \mathrm{H}), 2.02-2.67(\mathrm{~m}, 32 \mathrm{H}), 3.03-3.64 \mathrm{ppm}(\mathrm{m}, 16 \mathrm{H}$, overlapped with $\mathrm{CD}_{3} \mathrm{OD}$ peak at 3.31); MS(MALDI-TOF) $\mathrm{m} / \mathrm{z}$ calcd. for $\mathrm{C}_{92} \mathrm{H}_{189} \mathrm{~N}_{28} \mathrm{O}_{11} 1863.6681$, found $1863.51\left[\mathrm{M}^{+}+\mathrm{H}\right] ; \mathrm{m} / \mathrm{z}$ calcd. for $\mathrm{C}_{92} \mathrm{H}_{188} \mathrm{~N}_{28} \mathrm{O}_{11} \mathrm{Na} 1885.65$, found $1884.79\left[\mathrm{M}^{+}+\mathrm{Na}-1\right]^{+}$.

\subsection{Preparation of MEND}

MEND were prepared using the lipid-film hydration method, as previously described [13]. Briefly, plasmid DNA dissolved in 10 mM HEPES buffer (pH 7.4) (0.1 $\mathrm{mg} / \mathrm{ml}$ ) was mixed dropwise, while vortexing, with either a PLL solution (N/P ratio 2.4) or with different sorbitol-based transporters (N/P ratio 3) to condense pDNA. The codensed DNA suspension $(0.25 \mathrm{ml})$ was added to a lipid film containing $137.5 \mathrm{nmol}$ lipids [DOPE/CHEMS = 9:2 (molar ratio)], followed by incubation for $10 \mathrm{~min}$ at RT to hydrate the lipid film. The hydrated lipid film was then sonicated for $1 \mathrm{~min}$ in a bath-type sonicator (85 W, Aiwa Co., Tokyo, Japan) to construct MEND by coating the condensed DNA core with lipids. An aqueous solution of either different sorbitol-based transporters or STR-R8 (5 or 8 mole \% of total lipid) was added to the suspension and the mixtures were incubated for $30 \mathrm{~min}$ at RT to attach R8 or other transporters to the MEND envelope. In the case of MEND encapsulating siRNA, the siRNA solution was added dropwise to a solution of STR-R8 or other transporters under vortexing at room temperature (N/P ratio 
3). After the condensation of siRNA, $0.25 \mathrm{ml}$ of the condensed siRNA suspension was added to the lipid film, formed by the evaporation of a chloroform solution of $137.5 \mathrm{nmol}$ lipids, $[\mathrm{DOPE} / \mathrm{PA}=7: 2$ (molar ratio)] on the bottom of a glass tube, followed by an incubation for $10 \mathrm{~min}$ at RT to hydrate the lipids. The glass tube was then sonicated for about $1 \mathrm{~min}$ in a bath-type sonicator as described previously. An aqueous solution of STR-R8 (5 mole \% of total lipid) was added to the suspension and the mixtures were incubated for $30 \mathrm{~min}$ at RT. The hydrodynamic diameter was measured by a quasi-elastic light scattering method and the zeta-potential was determined electrophoretically by means of an electrophoretic light scattering spectrophotometer (ELS-8000, Otsuka electronics, Japan).

\subsection{Transfection assay}

HeLa, NIH3T3 or HeLa cells, which stably express luciferase $\left(\sim 10^{8}\right.$ RLU/mg protein), were cultured in a 24 -well plate (40000 cells per well) one day before transfection. At transfection time, samples containing $0.4 \mu \mathrm{g}$ of DNA or siRNA suspended in $0.25 \mathrm{ml}$ of serum-free DMEM were added to each well and incubated for 3 hr at $37^{\circ} \mathrm{C}$. Next, $1 \mathrm{ml}$ of DMEM containing $10 \%$ FBS was added to the cells, followed by incubation for $21 \mathrm{hr}$. The cells were then washed and solubilized with reporter lysis buffer. Luciferase activity of the cell lysate was measured in the presence of a luciferase assay reagent by means of a luminometer (Luminescencer-PSN, ATTO, Japan). The amount of total protein was determined using a BCA protein assay kit (PIERCE, Rockford, IL). Silencing effect was determined relative to cells treated with control siRNA (Anti-GFP).

\subsection{Electrophoresis}

Samples of DNA cores $(0.2 \mu \mathrm{g})$ condensed with different sorbitol-based transporters were treated with increasing concentrations of Poly(A) RNA for 15 min in the presence of an import buffer (HEPES $20 \mathrm{mM}$, potassium acetate $110 \mathrm{mM}$, sodium acetate $3 \mathrm{mM}$, magnesium acetate $2 \mathrm{mM}$, EGTA.4Na $0.5 \mathrm{mM}$, DTT $2 \mathrm{mM}$ ) to release the plasmid DNA. Elecrophoresis was performed on $1 \%$ agarose gel at $100 \mathrm{~V}$ for $30 \mathrm{~min}$, and the gel was then stained with ethidium bromide.

\subsection{Statistical Analysis}

Comparisons between multiple treatments were made using one way analysis of variance ANOVA, followed by the Student-Newman-Keuls test. In the case of Fig. 7, comparisons between pairs were made using a two-tail Student's t-test. 


\section{Results}

\subsection{Synthesis of sorbitol-based lipidated transporters}

The hydroxyl group in the protected intermediate (4), available from previous studies [21], was condensed with the corresponding carboxylic acid, i.e. dodecanoic acid (C12), tetracosanoic acid (C24), and triacontanoic acid (C30), in the presence of 1-(3-dimethylaminopropyl)-3-ethylcarbodiimide hydrochloride (EDC) and 4-dimethylaminopyridine (DMAP) in dichloromethane at RT to give the acylated products in 74-80\% yield (Fig. 1 and Supporting Information, Scheme 1). The $N$-tert-butylcarbonyl (Boc) and $O$-trityl (Tr) protecting groups were efficiently removed by treatment with ethyl acetate saturated with gaseous $\mathrm{HCl}$ at $\mathrm{RT}$ to give lipidated transporters 1a-c. For the synthesis of the histidine-containing triacontanoylated transporter (compound 2), intermediate 4 was first acylated with triacontanoic acid, the $O$-trityl group was selectively removed with trifluoroacetic acid (TFA) in dichloromethane at RT over $\mathrm{SiO}_{2}$, and $\mathrm{N}$-Cbz-L-histidine was attached to the hydroxyl group with EDC and DMAP. Then, the Boc groups were removed from the guanidine moieties as described above. Similarly, the protected intermediate (5), synthesized in previous studies [21], was acylated with triacontanoic acid and the protecting groups were removed to give transporter 3 in good yield (Fig. 1 and Supporting Information, Scheme 2).

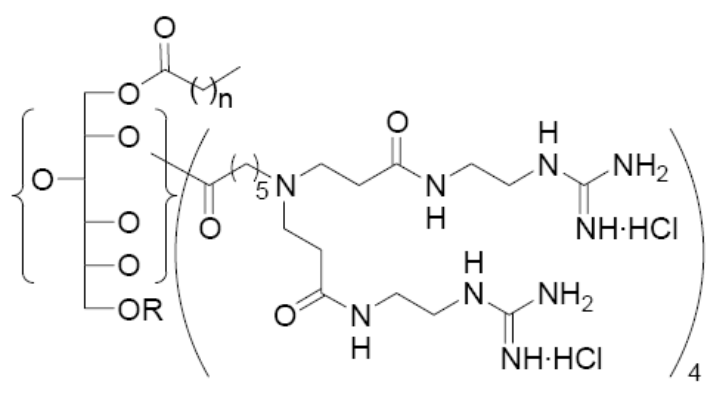

1a. $R=H, n=10$
b. $R=H, n=22$
c. $R=H, n=28$

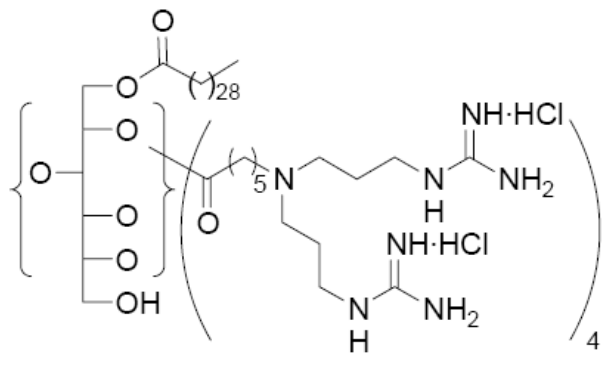

3

Figure 1

Structures of lipidated transporters used in the present study

Compounds 1a to 1c differ in the number of carbon atoms (n) in the acyl chains. Compound 2 differs from 1c in the structure of the $\mathrm{R}$ group $(\mathrm{Cbz}=$ carbobenzyloxy). Compound $\mathbf{3}$ differs from 1c in the linker chain type. 


\subsection{Lipidated sorbitol-based transporters as DNA condensing agents}

We evaluated the utility of differently lipidated sorbitol-based transporters as DNA condensers. Plasmid DNA was first condensed with different transporters at an N/P ratio of 3/1 to form condensed cores. These cores (ranging 61-93 $\mathrm{nm}$ in diameter) were then encapsulated in a lipid envelope composed of DOPE and CHEMS (molar ratio = 9:2). The produced particles were then modified with STR-R8 (5 mole \% of total lipid). Our previously reported nanoparticles which contain DNA condensed with the commonly used polycation (PLL) served as a control [16]. Characterization of different nanoparticles is shown in Table 1. Nanoparticles showed a diameter ranging from 230 to $305 \mathrm{~nm}$ and all were positively charged (31 to $53 \mathrm{mV}$, data not shown). Transfection activity of the series 1a-c decreased as chain length of the condenser increased: 1a (C12) $>\mathbf{1 b}(\mathrm{C} 24)>\mathbf{1 c}(\mathrm{C} 30)$ (Fig. 2). It is noteworthy that the transfection activity of 1a (C12) was increased 6-fold compared to the same compound carrying a C30 lipid chain, 1c. In particular, the transfection activity of 1a was greater than that of the original MEND system that used PLL as a condenser. Use of $\mathbf{3}$ did not increase transfection activity compared to 1c, which has the same lipid chain, but a different linker attached to the guanidine residues. In addition, adding a histidine moiety to $\mathbf{1 c}$ as in transporter $\mathbf{2}$, to provide a possible protonation site, decreased the transfection activity by approximately 4-fold (Fig. 2). Therefore, compound 1a, which has a shorter lipid chain but lacks a histidine residue, seems to be the optimal condensing agent for the core of the R8-MEND system.

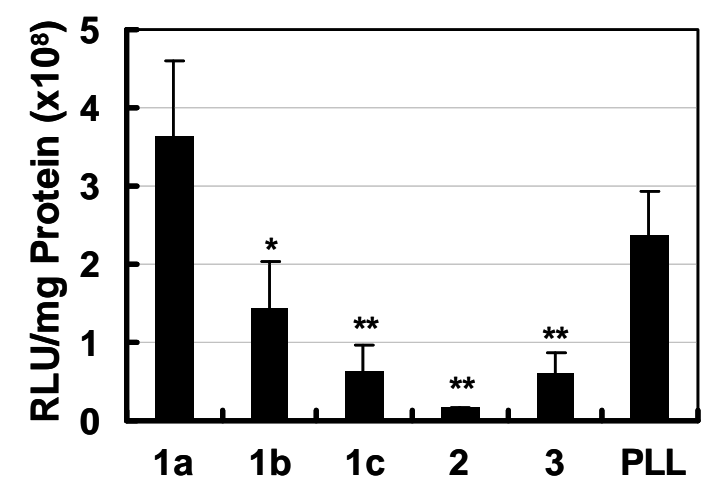

\section{Figure 2}

Transfection activities of different MEND prepared using different DNA cores

HeLa cells were transfected with different MEND particles containing luciferase-encoding pDNA. pDNA was condensed with different lipidated sorbitol-based molecular transporters (as shown in Fig. 1) or with PLL. The condensed DNA particles were then coated with a lipid envelope (DOPE/CHEMS), which was further modified with STR-R8 (5 mole \% of total lipids). Luciferase activity was measured $24 \mathrm{hr}$ after transfection and is expressed as relative light units (RLU) per mg of protein. Each bar represents the mean of 3 different experiments performed in triplicate. Error bars show the S.E.M $\left({ }^{*} \mathrm{P}<0.05, * * \mathrm{P}<0.01\right.$, compared to compound 1a). 


\section{Table 1}

Characterization of different MENDs prepared using different DNA cores (surface ligand was fixed as STR-R8)

\begin{tabular}{cc}
\hline Core & Diameter $(\mathrm{nm})^{\mathrm{a}}$ \\
\hline $1 \mathrm{a}$ & $231 \pm 22$ \\
$1 \mathrm{~b}$ & $281 \pm 25$ \\
$1 \mathrm{c}$ & $230 \pm 35$ \\
2 & $240 \pm 19$ \\
3 & $259 \pm 60$ \\
PLL & $305 \pm 30$ \\
\hline
\end{tabular}

${ }^{a}$ Data are means $\pm \mathrm{SD}$ of at least three different preparations

\subsection{Decondensation profile of condensed cores}

We tried to understand why gene expression improved when transporters with shorter lipid chains were used as condensers for the R8-MEND core. We investigated the decondensation profile of the cores as a possible rate-limiting factor that interferes with DNA recognition by transcription factors. It is possible that the driving force for decondensation is the replacement of pDNA with negative intracellular counterparts. Therefore, we investigated the stability of pDNA cores against poly(A) RNA, a negatively charged counterpart, using the gel retardation assay. Plasmid DNA was condensed with different lipidated transporters at an N/P ratio of 3/1. The condensed pDNA was then incubated with varying amounts of poly(A) RNA and subjected to gel electrophoresis. In the absence of RNA, only a small amount of pDNA migrated through the cells, suggesting that pDNA was bound to the condensers (Fig. 3A). As the amount of RNA increased, the DNA migration pattern started to resemble that of naked pDNA, indicating that decondensation had occurred. Quantitative comparison of decondensation efficiency is shown in Fig. 3B. Cores condensed with compounds $\mathbf{2}$ and $\mathbf{3}$ showed very poor decondensation, suggesting a hindered decondensation in the nucleus. Using a large amount of RNA $(0.8 \mu \mathrm{g})$, the decondensation efficiency of the series 1a-c was as follows: 1b $(\mathrm{C} 24)>\mathbf{1 a}(\mathrm{C} 12)>\mathbf{1 c}(\mathrm{C} 30)$. In the case of $\mathbf{1 a}(\mathrm{C} 12)$ and $\mathbf{1 b}(\mathrm{C} 24)$, migration of pDNA was clearly detected, indicating that the decondensation efficiency of these two compounds was much better than that of the other compounds. Fig. 4 shows the relation between decondensation efficiency and transfection efficiency. We assumed that the cores are exposed to high and variable polyanions intracellularly. Therefore, we used the data from the higher amounts of RNA $(0.8 \mu \mathrm{g})$ to confirm complete decondensation of the cores. Although we expected a linear relationship between decondensation and transfection efficiencies, experimental results were somewhat different. A pseudo-bell-shaped relationship was found since cores prepared with compound $\mathbf{1 b}$ 
showed higher decondensation efficiency but lower transfection activities compared to 1a. Similarly, the decondensation of cores prepared with 1c was higher than that of $\mathbf{3}$, although transfection activities of these two compounds were similar. These results suggest that cores prepared with shorter lipid chains (C12 and C24) are more easily decondensed. However, there is an optimum value of decondensation to obtain the highest transfection activities. Compound 2 showed poor decondensation which correlates with its low transfection activities.

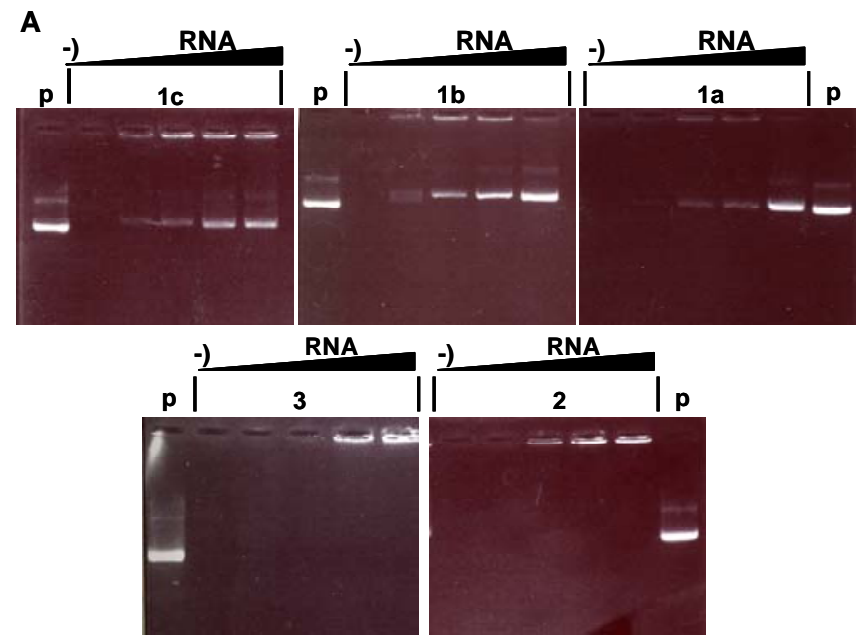

B

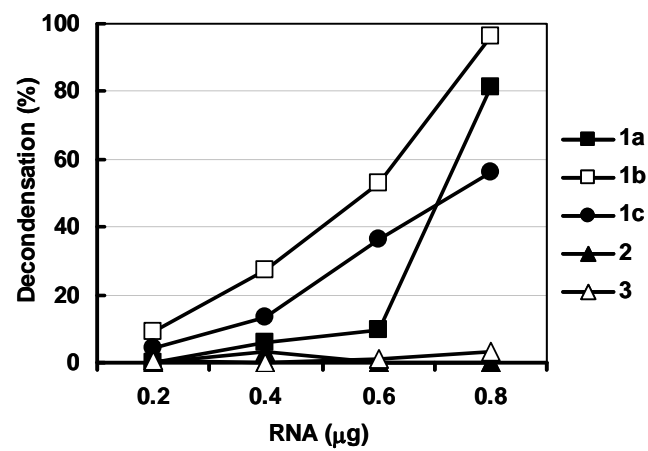

Figure 3

Evaluation of decondensation of DNA cores prepared using different lipidated sorbitol-based molecular transporters

A. Migration pattern of condensed DNA cores in agarose gel. Samples containing $0.2 \mu \mathrm{g}$ DNA were treated with various amounts of poly(A) RNA $(0,0.2,0.4,0.6$ and $0.8 \mu \mathrm{g})$ to release DNA from the condensers. Electrophoresis was performed on a $1 \%$ agarose gel at $100 \mathrm{~V}$ for $30 \mathrm{~min}$. Naked plasmid DNA (p) was used as a control. B. Quantification of the decondensation efficiency of different DNA cores. The amount of released DNA was divided by $0.2 \mu \mathrm{g}$ and multiplied by 100 to obtain the decondensation efficiency.

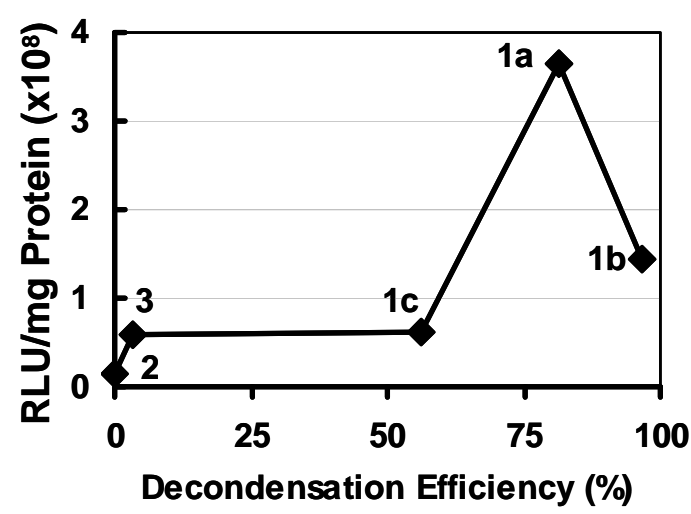

Figure 4

Relation between decondensation efficiency and transfection activities

Decondensation efficiency of different cores (obtained from Fig. 3B) was plotted against transfection activities of different MENDs (obtained from Fig. 2). 


\subsection{Applicability of lipidated sorbitol-based transporters as siRNA-compacting agents}

We recently demonstrated that STR-R8 is effective for the formation of siRNA core particles [23]. Because common condensers (i.e. PLL and protamine) cannot form stable siRNA particles, the presence of both a hydrophobic and a cationic group is essential for the formation of complexes with short RNA. Because the transporters used in this study are composed of hydrophobic and cationic moieties within a single molecule, we investigated the utility of these transporters in the preparation of siRNA cores. Anti-luciferase siRNA cores were formed using either different transporters or STR-R8 at an N/P ratio of $3 / 1$. The siRNA cores were then coated with fusogenic lipid (DOPE/PA) and further modified with STR-R8. Characterization of different nanoparticles is shown in Table 2. Very efficient gene knockdown was observed for all of the tested transporters (Fig. 5). Hence, these compounds were found to be very useful as siRNA condensers. The MEND encapsulating 1a (C12) cores showed the highest silencing effect, confirming the superiority of compounds with shorter lipid chains as condensers. Silencing effect with 1a was higher than that of our previously developed system using STR-R8 as a condenser [23]. In addition, $\mathbf{1 b}(\mathrm{C} 24)$ and 1c (C30) produced results comparable to that obtained using STR-R8.

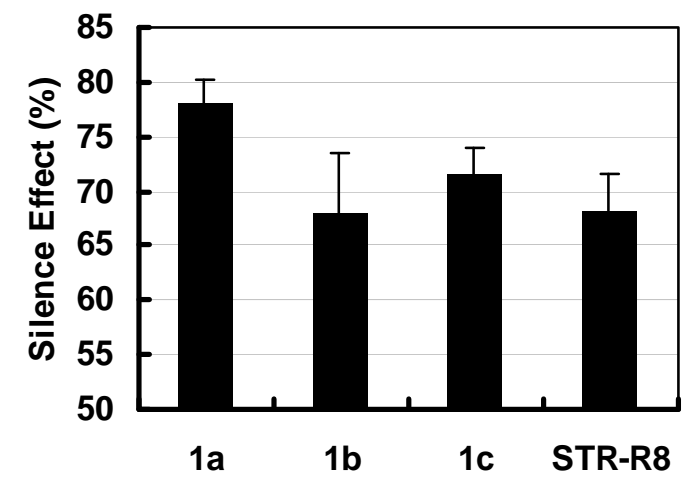

\section{Figure 5}

Silencing effect of different MENDs prepared using different siRNA condensed cores

Suspensions of MEND containing $0.4 \mu \mathrm{g}$ siRNA were added to transformed luciferase-stable HeLa cells. siRNA was condensed with selected lipidated sorbitol-based molecular transporters (as shown in Fig. 1) or with STR-R8. The condensed cores were then coated with a lipid envelope (DOPE/PA). The lipid envelope was further modified with STR-R8 (5 mole \% of total lipids). Luciferase activity was measured $24 \mathrm{hr}$ after transfection. Silencing effect was calculated by dividing luciferase activities (RLU/mg protein) of treated cells by that of cells treated with non-specific siRNA (anti-GFP siRNA) and multiplying by 100. Each bar represents the mean of 3 different experiments performed in triplicate. Error bars show the S.E.M. 


\section{Table 2}

Characterization of different MENDs prepared using different siRNA cores (surface ligand was fixed as STR-R8)

\begin{tabular}{cc}
\hline Core & Diameter $(\mathrm{nm})^{\mathrm{a}}$ \\
\hline $1 \mathrm{a}$ & $264 \pm 30$ \\
$1 \mathrm{~b}$ & $295 \pm 91$ \\
$1 \mathrm{c}$ & $267 \pm 61$ \\
STR-R8 & $250 \pm 26$ \\
\hline
\end{tabular}

${ }^{\mathrm{a}}$ Data are means $\pm \mathrm{SD}$ of at least three different preparations

\subsection{Lipidated sorbitol-based transporters as surface-modifying ligands of MEND}

We have previously shown that modification with STR-R8 significantly enhanced cellular uptake and improved intracellular trafficking of lipid vesicles [15,16,24]. Here, the applicability of the lipidated sorbitol-based transporters as surface ligands in the MEND system was evaluated. Because these transporters possess hydrophobic lipid chains (C12, C24 or C30), they are expected to spontaneously insert into the lipid membrane, resulting in surface modification of the MEND. This expectation was confirmed by the high positive charge on the modified particles $(33-45 \mathrm{mV}$, data not shown). Fig. 6 shows that the transfection activity of MEND modified with 1c (C30) was higher than the activity of MEND modified with short-chain transporters, 1a, or STR-R8 (approximately a 2.4- and 3.3-fold increase, respectively). Therefore, longer lipid chains are more effective surface-modifying agents. The transfection activity of 1a (C12) was comparable with that of STR-R8, which has a somewhat similar short chain. A small difference in favor of compound 1a was observed, indicating that guanidine groups on this particular scaffold equally or more effectively interact with cell membranes. Addition of histidine, as in compound 2 , decreased transfection activity by approximately 4.4-fold, indicating that surface modification with a compound containing a histidine group is not useful. Interestingly, compound $\mathbf{3}$ produced the highest activities [approximately a 4.2-fold increase compared to STR-R8], indicating that this transporter is a particularly effective surface-modifying ligand for the improvement of cellular uptake. The diameter of different nanoparticles is shown in Table 3. 


\section{Table 3}

Characterization of different MENDs prepared using PLL/DNA cores and modified with different surface ligands

\begin{tabular}{cc}
\hline Surface Ligand & ${\text { Diameter }(\mathrm{nm})^{\mathrm{a}}}^{\text {1a }}$ \\
1b & $399 \pm 44$ \\
$1 \mathrm{c}$ & $368 \pm 34$ \\
2 & $365 \pm 49$ \\
3 & $404 \pm 51$ \\
STR-R8 & $350 \pm 55$ \\
\hline
\end{tabular}

${ }^{a}$ Data are means \pm SD of at least three different preparations

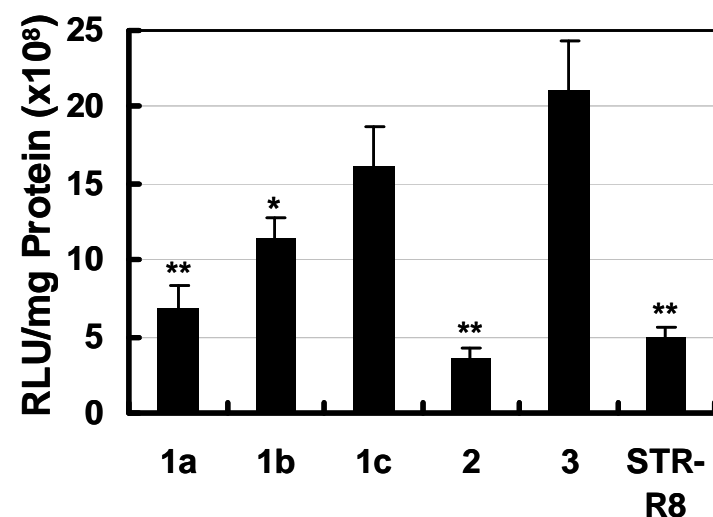

Figure 6

Transfection activities of different MENDs prepared with different surface ligands

HeLa cells were transfected with different MEND particles containing luciferase-encoding pDNA. pDNA was condensed with PLL. The condensed DNA particles were then coated with a lipid envelope (DOPE/CHEMS). The lipid envelope was further modified with different lipidated sorbitol-based molecular transporters (as shown in Fig. 1) or with STR-R8 (8 mole \% of total lipids). Luciferase activity was measured $24 \mathrm{hr}$ after transfection and is expressed as relative light units (RLU) per mg of protein. Each bar represents the mean of 3 different experiments performed in triplicate. Error bars show the S.E.M. $\left({ }^{*} \mathrm{P}<0.05\right.$, $* * \mathrm{P}<0.01$, compared to compound $\mathbf{3}$ ).

In a separate direct comparison, the optimized system prepared with compound $\mathbf{3}$ as a surface ligand (MEND3) favorably competes with Lipofectin, a commercially available transfection reagent, in two different cell lines (Fig. 7). The activity of MEND3 was $\sim 9$-fold greater than that of Lipofectin in HeLa cells. The MEND3 system also produced significantly higher gene expression than Lipofectin in NIH3T3 cells ( 2.4-fold). Notably, the transfection activity of the MEND modified with compound 3 was higher in HeLa cells compared to that in NIH3T3 cells. Hence, the optimized MEND has a great potential as a rationally designed non-viral gene delivery system with a high transfection activity. 
A. HeLa

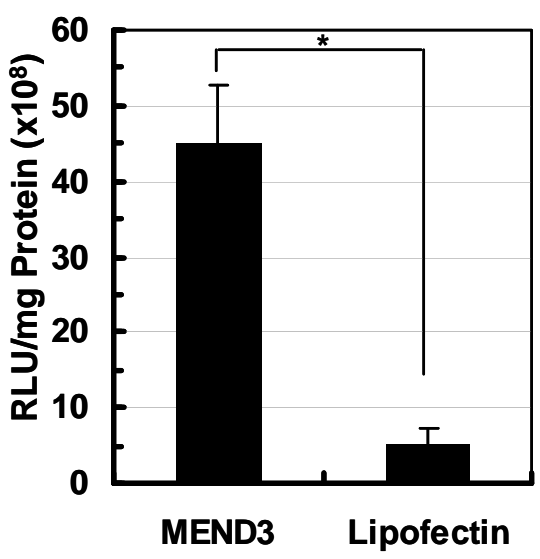

B. NIH3T3

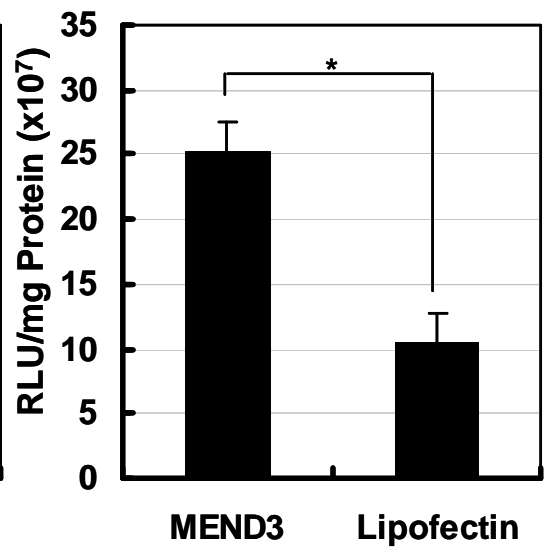

\section{Figure 7}

\section{Comparing transfection activities of MEND3 and Lipofectin lipoplexes}

HeLa (A) or NIH3T3 (B) cells were transfected with luciferase-encoding pDNA complexed with the commercial transfection reagent, Lipofectin, or encapsulated in optimized MEND particles modified with compound 3 (MEND3). Luciferase activity was measured $24 \mathrm{hr}$ after transfection and is expressed as relative light units (RLU) per mg of protein. Each bar represents the mean of 3 different experiments performed in triplicate. Error bars show the S.E.M. $\left({ }^{*} \mathrm{P}<0.01\right)$. 


\section{Discussion}

We previously developed a multifunctional, envelope-type nano-device as an efficient non-viral gene delivery system $[13,16]$. This virus-mimicking system is based on a core-shell structure, in which a condensed DNA core is encapsulated by a lipid envelope that has the ability to carry multiple functional devices for optimization. A key functional component, which improved the cellular uptake and intracellular trafficking was STR-R8, a lipidated octaarginine peptide $[15,24]$. The stearyl moiety is anchored onto the lipid vesicle, thus leaving the R8 peptide free to interact with the cell membrane. A sucrose density gradient centrifugation has shown that most of the DNA fraction was colocalized with the lipid fraction [13]. In addition, electron microscopy images have confirmed the formation of a core/shell structure of the MEND system in which the condensed DNA was encapsulated in the lipid envelope [16,25]. In an attempt to find more efficient functional components for the MEND system, we examined the possibility of using novel lipidated, sorbitol-based molecular transporters as the condenser or surface modifier. Although designed to mimic the HIV-1 Tat peptide, these transporters have substantially different activities in vivo and in vitro [21]. They are also expected to be more resistant to the activity of endogenous enzymes. The transporters used all possess octaguanidine bases on the sorbitol scaffold. The octaguanidine bases are intended to replace the octaarginine peptide conferring a positive charge to the structure. In addition, these compounds have different lipid groups, which vary in carbon chain length, attached to the sorbitol scaffold. The lipid chains enhance the DNA/siRNA condensation ability of the transporters and also act as anchors to the lipid surface of the MEND system.

We previously demonstrated that the rate-limiting step of transgene expression using non-viral vectors is the post-nuclear delivery process [26]. A mechanism relevant to the present study is poor decondensation of DNA in the nucleus. Therefore, we hoped that changing the DNA condenser might improve transgene expression activity. Thus, we investigated the utility of novel sorbitol-based transporters as condensers of DNA. We also examined the possible use of these transporters as surface modifiers of the MEND system to achieve higher cellular uptake. As expected, the results described above show that these novel transporters act as condensing agents for core formation and as surface-modifying agents for the enhancement of cellular uptake. However, of special importance is the observation that a good DNA condenser is not necessarily a good surface ligand and vice versa, at least in this series of molecular devices. For example, compound 1a with a short lipid chain $(\mathrm{C} 12)$ demonstrated relatively good performance as a condensing agent (Fig. 2), but was less effective as a surface ligand (Fig. 6). In contrast, 
compound 1c with a long lipid chain (C30) was a good surface ligand, but a relatively poor condenser. Similarly, compound 3 (C30) with a different linker-chain type was found more efficient than 1c (C30) as a surface ligand, but not as a condenser.

Regarding the use of these transporters as condensers, MEND prepared with DNA cores condensed with short lipid-chain transporters were more efficient than those condensed with longer lipid chains (Fig. 2). The efficiency of an intermediate chain length (C24) was approximately half-way between the efficiency of C30 and C12. We investigated the decondensation efficiency of different cores as a possible limiting step towards transfection. We hypothesized that facilitated decondensation might increase transfection activities. The use of compound 1a as a condenser produced the highest activities and these cores were easily decondensed. Meanwhile, using compound $\mathbf{1 c}$ as a condenser produced lower activities and decondensation of cores was more difficult. Presumably, particles condensed with long lipid-chain transporters are overly stabilized by the long hydrophobic groups of 1c (C30), thereby hindering decondensation in the nucleus. Cores prepared with compounds $\mathbf{2}$ and $\mathbf{3}$ (both with C30 carbon chain) were not easily decondensed which may explain their low transfection activities compared to compound 1a. However, a relationship between decondensation and transfection efficiencies suggested an interesting phenomenon since compound $\mathbf{1 b}$ which showed the highest decondensation was not the most efficient in terms of transfection. Therefore, facilitated decondensation is not necessarily advantageous for transfection and there is an optimum value of decondensation to achieve higher transfection. The easily decondensed cores may be more easily degraded. In addition, the decondensation efficiency of compound 1c was superior to that of 3 , indicating that linker pattern-type also affects decondensation efficiency. Despite the superiority of compound 1c compared to 3 regarding facilitated decondensation, both cores produced similar transfection activities which shows that factors other than decondensation may contribute to the overall activities. Decoating efficiency of different cores is a possible candidate. For example, a certain core may be more easily released from the lipid envelope and this is expected to increase its transfection activity. We also tested the importance of finding a potential protonation site, namely imidazole, on transfection activity of the transporters as in compound 2. The histidine-containing transporter 2 exhibited the lowest transfection yield and the lowest decondensation efficiency. This indicates that potential protonation sites do not facilitate decondensation. It should be noted that the term "decondensation" was used here to reflect the change of the structure of DNA from the condensed state to a relaxed state, which can migrate freely through the gel in a gel electrophoresis analysis.

We recently demonstrated that STR-R8 was very effective in the formation of 
siRNA core particles [23]. Because common condensers (i.e. PLL and protamine) cannot form compact siRNA particles, both hydrophobic and cationic groups are essential to the formation of complexes with short RNA. We examined the possible utility of the novel transporters described in this study in siRNA core formation (Fig. 5). All prepared MEND showed a silencing effect that was somewhat higher than that resulting from MEND encapsulating a STR-R8/DNA core. A significantly higher silencing effect was observed when the siRNA core was prepared with 1a. As explained earlier, cores prepared with shorter hydrophobic chains may more easily undergo decondensation in the cytosol. However, the decondensation seems more important during post-nuclear events because the effect on gene expression is greater than that on siRNA in the cytosol.

Regarding the use of these transporters as surface ligands, these transporters are expected to electrostatically bind to cell surface negative constituents such as heparan sulfate proteoglycans (HSPGs). The surface HSPGs may act as non-specific receptors for the guanidine-based transporters, similar to R8 and other PTD peptides, to facilitate their cellular uptake $[13,24,27]$. It was previously shown that the interaction between $\mathrm{R} 8$ peptide and HSPGs caused a re-arrangement of the cytoskeleton which facilitates the cellular uptake through endocytosis [27]. A similar interaction between guanidine-based transporters and surface HSPGs is possible, although this was not studied here. Although there is no specific receptors for R8 or guanidine-based transporters on the cell surface, the term "ligand" was used here based on a possible role of HSPGs as non-specific receptors for these cationic moieties.

As for the efficiency of guanidine-based transporters as surface ligands, we found that MEND modified with longer lipid chains had transfection activities higher than those modified with shorter chains (Fig. 6). Among the series of guanidine transporters (compounds 1a-c), it appears that the long lipid chain (C30) more effectively enhances cellular uptake than the short lipid chain (C12), perhaps because the short lipid chain does not allow for stable insertion of the transporter into the MEND lipid envelope. It is also possible that residual chain flexibility after part of the chain has been inserted into the liposome is needed for cell-surface interaction and, thus, for efficient uptake. In addition, MEND modified with compound 3 (C30) had a greater transfection activity than MEND modified with 1c (C30). The difference in gene expression may be due to differences in cellular uptake and/or intracellular trafficking. The trend evident in Fig. 6 is consistent with the observation that the cellular uptake efficiency of the parent compound of $\mathbf{3}$, namely the transporter without a lipid chain, is better than that of the parent compound of 1c [21]. Thus, we hypothesize that the difference in gene expression is mainly due to differences in cellular uptake rather than endosomal escape. 
It is worth mentioning that the transporters effect as surface ligands was higher than their effect when used as condensers. This is evident from the absolute values of transfection activities. MEND prepared with an optimum condenser, 1a, produced transfection activities lower than that prepared with an optimal surface ligand, 3 (Fig. 2 and 6).

The large variability in the performance of compound $\mathbf{3}$ is very interesting. This compound is a relatively poor device when it comes to direct condensation with DNA, presumably due to poor decondensation. However, the same compound tends to be of a great value when used as a surface ligand on a lipid envelope encapsulating DNA. In other words, function of this compound requires a particular topology or separation from DNA. The lipid envelope of the MEND system may meet this requirement, validating the concept of MEND as a way to control the topology of functional devices. Finally, an optimized MEND prepared using compound $\mathbf{3}$ as the surface ligand proved to be a highly efficient non-viral gene delivery system that is superior to the commonly used Lipofectin (Fig. 7). This system has additional advantages over common lipoplexes for in vivo applications, because the lipid envelope provides better DNA protection and can easily incorporate several functional devices, such as polymers for long circulation in the blood or ligands for selective targeting to particular tissues.

In conclusion, the novel lipidated sorbitol-based transporters developed in this study proved to be highly useful agents for the formation of core siRNA and plasmid DNA. In addition, some of these transporters proved to be very efficient surface-modifying ligands for an envelope-type gene delivery system. Compound 1a with a short lipid chain (C12) is particularly useful for condensation; whereas, compound 3 with a long lipid chain (C30) and a different linker type is optimal for surface modification. These findings may have significant implications in the future design and development of non-viral gene delivery systems. 


\section{Acknowledgments}

This work was financially supported by Korean MOEHR (BK-21) and MOST (National Frontier Research Program administered through KRICT/CBM), by Grants-in-Aid for Scientific Research (A) from the Ministry of Education, Culture, Sports, Science and Technology of Japan, and by Grants-in-Aid for Scientific Research on Priority Areas from the Japan Society for the Promotion of Science. 


\section{References}

[1] D.A. Williams, C. Baum, Medicine. Gene therapy--new challenges ahead. Science (New York, N.Y 302(5644) (2003) 400-401.

[2] J. Kaiser, Gene therapy. Putting the fingers on gene repair. Science (New York, N.Y 310(5756) (2005) 1894-1896.

[3] K. Kostarelos, A.D. Miller, Synthetic, self-assembly ABCD nanoparticles; a structural paradigm for viable synthetic non-viral vectors. Chemical Society reviews 34(11) (2005) 970-994.

[4] E. Mastrobattista, M.A. van der Aa, W.E. Hennink, D.J. Crommelin, Artificial viruses: a nanotechnological approach to gene delivery. Nature reviews 5(2) (2006) 115-121.

[5] D.R. Gius, S.A. Ezhevsky, M. Becker-Hapak, H. Nagahara, M.C. Wei, S.F. Dowdy, Transduced p16INK4a peptides inhibit hypophosphorylation of the retinoblastoma protein and cell cycle progression prior to activation of Cdk2 complexes in late G1. Cancer Res 59(11) (1999) $2577-2580$.

[6] J. Yuan, A. Kramer, F. Eckerdt, M. Kaufmann, K. Strebhardt, Efficient internalization of the polo-box of polo-like kinase 1 fused to an Antennapedia peptide results in inhibition of cancer cell proliferation. Cancer Res 62(15) (2002) 4186-4190.

[7] J.S. Wadia, R.V. Stan, S.F. Dowdy, Transducible TAT-HA fusogenic peptide enhances escape of TAT-fusion proteins after lipid raft macropinocytosis. Nat Med 10(3) (2004) 310-315.

[8] I. Nakase, M. Niwa, T. Takeuchi, K. Sonomura, N. Kawabata, Y. Koike, M. Takehashi, S. Tanaka, K. Ueda, J.C. Simpson, A.T. Jones, Y. Sugiura, S. Futaki, Cellular uptake of arginine-rich peptides: roles for macropinocytosis and actin rearrangement. Mol Ther 10(6) (2004) 1011-1022.

[9] S. Futaki, W. Ohashi, T. Suzuki, M. Niwa, S. Tanaka, K. Ueda, H. Harashima, Y. Sugiura, Stearylated arginine-rich peptides: a new class of transfection systems. Bioconjug Chem 12(6) (2001) 1005-1011.

[10] V.P. Torchilin, T.S. Levchenko, R. Rammohan, N. Volodina, B. Papahadjopoulos-Sternberg, G.G. D'Souza, Cell transfection in vitro and in vivo with nontoxic TAT peptide-liposome-DNA complexes. Proc Natl Acad Sci U S A 100(4) (2003) 1972-1977.

[11] C. Rudolph, C. Plank, J. Lausier, U. Schillinger, R.H. Muller, J. Rosenecker, Oligomers of the arginine-rich motif of the HIV-1 TAT protein are capable of transferring plasmid DNA into cells. The Journal of biological chemistry 278(13) (2003) 11411-11418.

[12] L. Hyndman, J.L. Lemoine, L. Huang, D.J. Porteous, A.C. Boyd, X. Nan, HIV-1 Tat protein transduction domain peptide facilitates gene transfer in combination with cationic liposomes. $\mathrm{J}$ 
Control Release 99(3) (2004) 435-444.

[13] K. Kogure, R. Moriguchi, K. Sasaki, M. Ueno, S. Futaki, H. Harashima, Development of a non-viral multifunctional envelope-type nano device by a novel lipid film hydration method. J Control Release 98(2) (2004) 317-323.

[14] I.A. Khalil, S. Futaki, M. Niwa, Y. Baba, N. Kaji, H. Kamiya, H. Harashima, Mechanism of improved gene transfer by the N-terminal stearylation of octaarginine: enhanced cellular association by hydrophobic core formation. Gene therapy 11(7) (2004) 636-644.

[15] I.A. Khalil, K. Kogure, S. Futaki, H. Harashima, High density of octaarginine stimulates macropinocytosis leading to efficient intracellular trafficking for gene expression. The Journal of biological chemistry 281(6) (2006) 3544-3551.

[16] I.A. Khalil, K. Kogure, S. Futaki, S. Hama, H. Akita, M. Ueno, H. Kishida, M. Kudoh, Y. Mishina, K. Kataoka, M. Yamada, H. Harashima, Octaarginine-modified multifunctional envelope-type nanoparticles for gene delivery. Gene therapy 14(8) (2007) 682-689.

[17] P.A. Wender, D.J. Mitchell, K. Pattabiraman, E.T. Pelkey, L. Steinman, J.B. Rothbard, The design, synthesis, and evaluation of molecules that enable or enhance cellular uptake: peptoid molecular transporters. Proc Natl Acad Sci U S A 97(24) (2000) 13003-13008.

[18] P.A. Wender, J.B. Rothbard, T.C. Jessop, E.L. Kreider, B.L. Wylie, Oligocarbamate molecular transporters: design, synthesis, and biological evaluation of a new class of transporters for drug delivery. Journal of the American Chemical Society 124(45) (2002) 13382-13383.

[19] P. Zhou, M. Wang, L. Du, G.W. Fisher, A. Waggoner, D.H. Ly, Novel binding and efficient cellular uptake of guanidine-based peptide nucleic acids (GPNA). Journal of the American Chemical Society $125(23)$ (2003) 6878-6879.

[20] K.K. Maiti, O.Y. Jeon, W.S. Lee, D.C. Kim, K.T. Kim, T. Takeuchi, S. Futaki, S.K. Chung, Design, synthesis, and membrane-translocation studies of inositol-based transporters. Angewandte Chemie (International ed 45(18) (2006) 2907-2912.

[21] K.K. Maiti, W.S. Lee, T. Takeuchi, C. Watkins, M. Fretz, D.C. Kim, S. Futaki, A. Jones, K.T. Kim, S.K. Chung, Guanidine-containing molecular transporters: sorbitol-based transporters show high intracellular selectivity toward mitochondria. Angewandte Chemie (International ed 46(31) (2007) 5880-5884.

[22] K.K. Maiti, O.Y. Jeon, W.S. Lee, S.K. Chung, Design, synthesis, and delivery properties of novel guanidine-containing molecular transporters built on dimeric inositol scaffolds. Chemistry European Journal (Weinheim an der Bergstrasse, Germany) 13(3) (2007) 762-775.

[23] R. Moriguchi, K. Kogure, H. Akita, S. Futaki, M. Miyagishi, K. Taira, H. Harashima, A multifunctional envelope-type nano device for novel gene delivery of siRNA plasmids. International 
journal of pharmaceutics 301(1-2) (2005) 277-285.

[24] I.A. Khalil, K. Kogure, S. Futaki, H. Harashima, Octaarginine-modified liposomes: enhanced cellular uptake and controlled intracellular trafficking. International journal of pharmaceutics 354(1-2) (2008) 39-48.

[25] Y. Nakamura, K. Kogure, S. Futaki, H. Harashima, Octaarginine-modified multifunctional envelope-type nano device for siRNA. J Control Release 119(3) (2007) 360-367.

[26] S. Hama, H. Akita, R. Ito, H. Mizuguchi, T. Hayakawa, H. Harashima, Quantitative comparison of intracellular trafficking and nuclear transcription between adenoviral and lipoplex systems. Mol Ther 13(4) (2006) 786-794.

[27] I. Nakase, M. Niwa, T. Takeuchi, K. Sonomura, N. Kawabata, Y. Koike, M. Takehashi, S. Tanaka, K. Ueda, J.C. Simpson, A.T. Jones, Y. Sugiura, S. Futaki, Cellular uptake of arginine-rich peptides: roles for macropinocytosis and actin rearrangement. Mol Ther 10(6) (2004) 1011-1022. 


\section{SUPPORTING INFORMATION}

\section{Scheme 1. Synthesis of lipidated transporters 1 and 2}

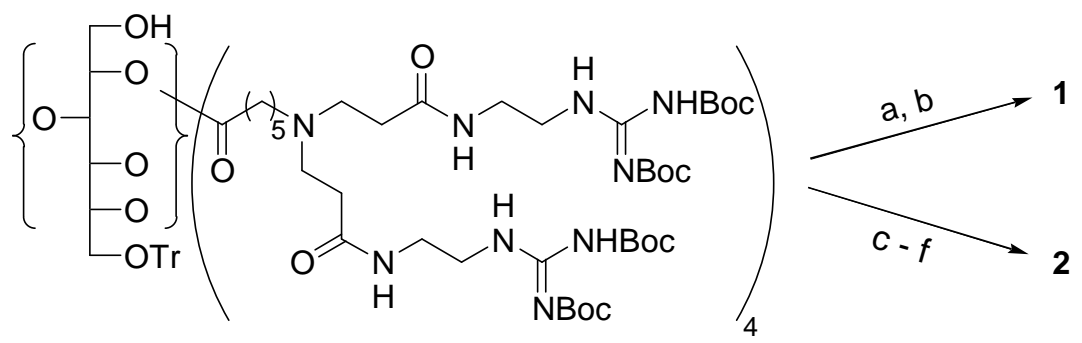

4

Reaction conditions: a. dodecanoic acid, tetracosanoic acid, or triacontanoic acid (2 equiv. each), $\mathrm{EDC} \cdot \mathrm{HCl}$ (2.5 equiv.), DMAP (0.7 equiv.), $\mathrm{CH}_{2} \mathrm{Cl}_{2}, \mathrm{rt}, 20 \mathrm{hr}, 74 \sim 80 \%$; b. saturated $\mathrm{HCl}(\mathrm{g})$ in EtOAc, rt, 20-30 hr, $80 \sim 85 \%$; c. triacontanoic acid (2 equiv.), $\mathrm{EDC} \cdot \mathrm{HCl}$ (2.5 equiv.), DMAP (0.7 equiv.), $\mathrm{CH}_{2} \mathrm{Cl}_{2}$, rt, $20 \mathrm{hr}, 75 \%$; d. 1\% TFA in $\mathrm{CH}_{2} \mathrm{Cl}_{2}$ over $\mathrm{SiO}_{2}, \mathrm{rt}, 68 \%$; e. N-Cbz-L-histidine (2.2 equiv.), EDC·HCl (3 equiv.), DMAP (1 equiv.), $\mathrm{CH}_{2} \mathrm{Cl}_{2}$, rt, 30 hr, 80 \%; f. saturated $\mathrm{HCl}$ (g) in EtOAc, rt, 20 hr, 76 \%.

\section{Scheme 2. Synthesis of lipidated transporter 3}

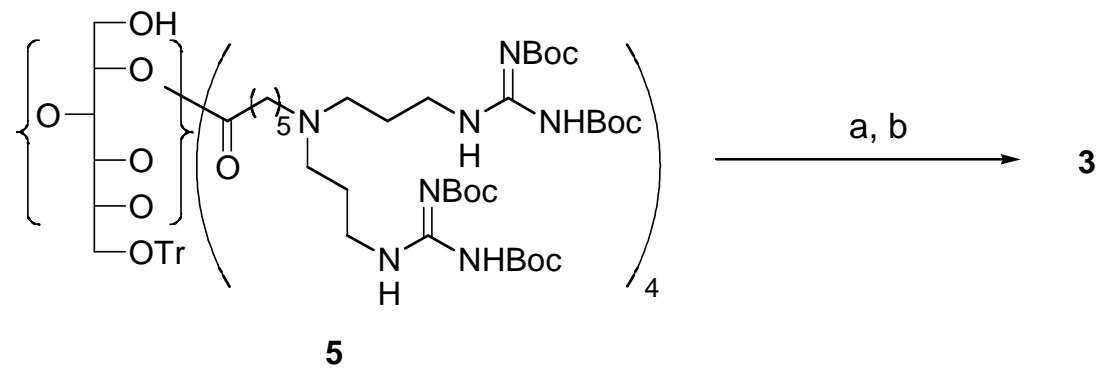

Reaction conditions: a. triacontanoic acid (2.5 equiv.), EDC $\cdot \mathrm{HCl}$ (3 equiv.), DMAP (0.5 equiv.), $\mathrm{CH}_{2} \mathrm{Cl}_{2}$, rt, 35 hr, $72 \%$; b. saturated $\mathrm{HCl}$ (g) in EtOAc, rt, $20 \mathrm{hr}, 85 \%$. 


\section{FIGURE LEGENDS}

\section{Figure 1}

\section{Structures of lipidated transporters used in the present study}

Compounds 1a to 1c differ in the number of carbon atoms (n) in the acyl chains. Compound 2 differs from $1 c$ in the structure of the $\mathrm{R}$ group $(\mathrm{Cbz}=$ carbobenzyloxy). Compound $\mathbf{3}$ differs from $\mathbf{1 c}$ in the linker chain type.

\section{Figure 2}

\section{Transfection activities of different MEND prepared using different DNA cores}

HeLa cells were transfected with different MEND particles containing luciferase-encoding pDNA. pDNA was condensed with different lipidated sorbitol-based molecular transporters (as shown in Fig. 1) or with PLL. The condensed DNA particles were then coated with a lipid envelope (DOPE/CHEMS), which was further modified with STR-R8 (5 mole \% of total lipids). Luciferase activity was measured $24 \mathrm{hr}$ after transfection and is expressed as relative light units (RLU) per mg of protein. Each bar represents the mean of 3 different experiments performed in triplicate. Error bars show the S.E.M $\left({ }^{*} \mathrm{P}<0.05,{ }^{* *} \mathrm{P}<0.01\right.$, compared to compound 1a).

\section{Figure 3}

Evaluation of decondensation of DNA cores prepared using different lipidated sorbitol-based molecular transporters

A. Migration pattern of condensed DNA cores in agarose gel. Samples containing $0.2 \mu \mathrm{g}$ DNA were treated with various amounts of poly(A) RNA $(0,0.2,0.4,0.6$ and 0.8 $\mu \mathrm{g})$ to release DNA from the condensers. Electrophoresis was performed on a $1 \%$ agarose gel at $100 \mathrm{~V}$ for $30 \mathrm{~min}$. Naked plasmid DNA (p) was used as a control. B. Quantification of the decondensation efficiency of different DNA cores. The amount of released DNA was divided by $0.2 \mu \mathrm{g}$ and multiplied by 100 to obtain the decondensation efficiency.

\section{Figure 4}

\section{Relation between decondensation efficiency and transfection activities}

Decondensation efficiency of different cores (obtained from Fig. 3B) was plotted against transfection activities of different MENDs (obtained from Fig. 2). 


\section{Figure 5}

\section{Silencing effect of different MENDs prepared using different siRNA condensed cores}

Suspensions of MEND containing $0.4 \mu \mathrm{g}$ siRNA were added to transformed luciferase-stable HeLa cells. siRNA was condensed with selected lipidated sorbitol-based molecular transporters (as shown in Fig. 1) or with STR-R8. The condensed cores were then coated with a lipid envelope (DOPE/PA). The lipid envelope was further modified with STR-R8 (5 mole \% of total lipids). Luciferase activity was measured $24 \mathrm{hr}$ after transfection. Silencing effect was calculated by dividing luciferase activities (RLU/mg protein) of treated cells by that of cells treated with non-specific siRNA (anti-GFP siRNA) and multiplying by 100 . Each bar represents the mean of 3 different experiments performed in triplicate. Error bars show the S.E.M.

\section{Figure 6}

\section{Transfection activities of different MENDs prepared with different surface ligands}

HeLa cells were transfected with different MEND particles containing luciferase-encoding pDNA. pDNA was condensed with PLL. The condensed DNA particles were then coated with a lipid envelope (DOPE/CHEMS). The lipid envelope was further modified with different lipidated sorbitol-based molecular transporters (as shown in Fig. 1) or with STR-R8 (8 mole \% of total lipids). Luciferase activity was measured $24 \mathrm{hr}$ after transfection and is expressed as relative light units (RLU) per mg of protein. Each bar represents the mean of 3 different experiments performed in triplicate. Error bars show the S.E.M. ( ${ }^{*} \mathrm{P}<0.05, * * \mathrm{P}<0.01$, compared to compound 3 ).

\section{Figure 7}

\section{Comparing transfection activities of MEND3 and Lipofectin lipoplexes}

HeLa (A) or NIH3T3 (B) cells were transfected with luciferase-encoding pDNA complexed with the commercial transfection reagent, Lipofectin, or encapsulated in optimized MEND particles modified with compound 3 (MEND3). Luciferase activity was measured $24 \mathrm{hr}$ after transfection and is expressed as relative light units (RLU) per $\mathrm{mg}$ of protein. Each bar represents the mean of 3 different experiments performed in triplicate. Error bars show the S.E.M. $\left({ }^{*} \mathrm{P}<0.01\right)$. 